\title{
Usefulness of Computed Tomographic Perfusion Imaging for Appropriate Diagnosis of Acute Cerebral Vessel Occlusion in Case of Anatomic Variations of the Circle of Willis
}

\author{
Jeyanthan Charles James, $\mathrm{MD}^{1}$, Daniel Richter, $\mathrm{MD}^{1}$, Laura Tomaske, $\mathrm{MD}^{1}$, Ruth Schneider, $\mathrm{MD}^{1}$, \\ Carsten Lukas, $\mathrm{MD}^{2}$, Felix Kaemmerer, $\mathrm{MD}^{2}$, Ralf Gold, MD, FEAN ${ }^{1}$, Christos Krogias, MD, FESO ${ }^{1}$ \\ ${ }^{1}$ Department of Neurology, St. Josef-Hospital, Ruhr-University Bochum, Bochum, Germany \\ ${ }^{2}$ Institute of Neuroradiology, St. Josef-Hospital, Ruhr-University Bochum, Bochum, Germany
}

\begin{abstract}
Mechanical thrombectomy (MT) is an effective treatment in patients with acute ischemic stroke (AIS) due to emergent large-vessel occlusion in the anterior circulation. Occlusion of the anterior cerebral artery (ACA) affects up to $15 \%$ of these patients. Here we report a case of an elderly patient with an successful MT of an embolic A2-segment occlussion with the anatomic variation of a triplication. Triplication of ACA is a rare anatomical variation, and the occlusion could have been easily overlooked in case of not performing the CT-perfusion (CTP) sequences. As anatomical variations of the circle of Willis are present in most subjects, CTA alone might be limited in the acute setting, particularly for young residents performing the first view on call. This case highlights the importance of including CTP in the initial CT-diagnostic algorithm in AIS patients who are basically eligible for recanalization therapies, irrespective of inconspicuous initial findings in CTA.
\end{abstract}

Key Words: Stroke; Thrombectomy; Perfusion imaging

\section{INTRODUCTION}

Mechanical thrombectomy (MT) is an effective, well established and guideline-recommended treatment in patients with acute ischemic stroke (AIS) due to emergent large-vessel occlusion in the anterior circulation. ${ }^{1}$ Primary or secondary embolic occlusion of the distal anterior cerebral artery (ACA) affects up to $15 \%$ of these patients. ${ }^{2}$

The ACA is a branch of the internal carotid artery (ICA) and gives off the anterior communicating artery. Pars precommunicalis is described as A1-segment, pars postcommunicalis as A2-segment.
The medial hemisphere is predominantly supplied by the ACA. ${ }^{3}$ Circulatory disorders of the ACA typically result to contralateral hemiparesis with accentuation of the lower extremity. Furthermore, a broad spectrum of complex cognitive, behavioral, and emotional disorders are described. ${ }^{4}$ Variations of the circle of Willis are well known and described in literature. $^{5-9}$

Here we report a case of a patient with an embolic stroke in the area of the ACA due to an occlusion of the proximal A2-segment with the anatomic variation of a triplication, so that occlusion can easily been overseen in computed to-

\section{Correspondence to:}

Christos Krogias, MD, FESO

Department of Neurology, St. JosefHospital, Ruhr-University Bochum, Gudrunstrasse 56, D-44791 Bochum, Germany

Tel: +492345090

Fax: +492345093072

E-mail: christos.krogias@rub.de

Received: March 7, 2021

Revised: May 20, 2021

Accepted: June 8, 2021

Copyright $\odot 2021$ Korean Society of Interventional Neuroradiology This is an Open Access article distributed under the terms of the Creative Commons Attribution Non-Commercial License (http://creativecommons.org/licenses/by-nc/4.0) which permits unrestricted non-commercial use, distribution, and reproduction in any medium, provided the original work is properly cited.

pISSN 2093-9043 eISSN 2233-6273 
mographic (CT)-angiography (CTA). The Institutional Review Board approved the publication of this material.

\section{CASE REPORT}

An elderly patient was presented with a severe left sided hemiparesis noticed by nurses of an external hospital while awaking in the morning at 7:00 AM. Last time seen normal was in the night at 10:00 PM the day before emergency hospital admission. The previous hospitalization of the patient was due to an acute decompensated heart failure.
Initial neurological examination documented an altered mental status with severe left sided hemiparesis (greater in leg than arm) with head and gaze deviation to the right in combination with hemineglect to the left, dysarthria and apraxia (National Institutes of Stroke Scale, NIHSS=15 points).

The patient was immediately transferred to our hospital as a "wake-up-stoke"-patient being potentially eligible for recanalization. In this context, the algorithm in our standard operating procedure provides that after exclusion of an intracerebral hemorrhage in the initial non-contrast CT, a CTA and CT-perfusion (CTP) is performed (Siemens Somatom ${ }^{\circledast}$ 64-slice CT system, Syngo ${ }^{\circledR}$ Volume Perfusion CT Neuro
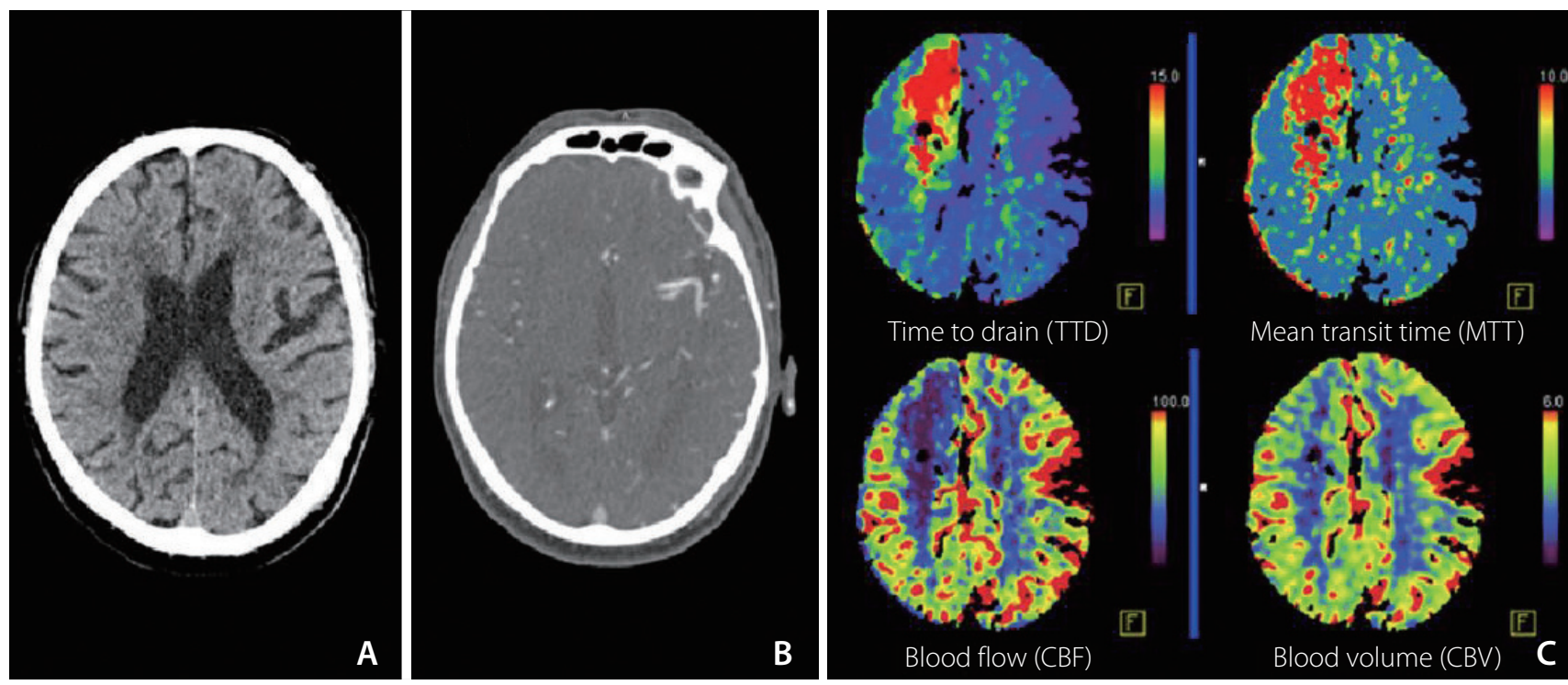

Mean transit time (MTT)

F

.
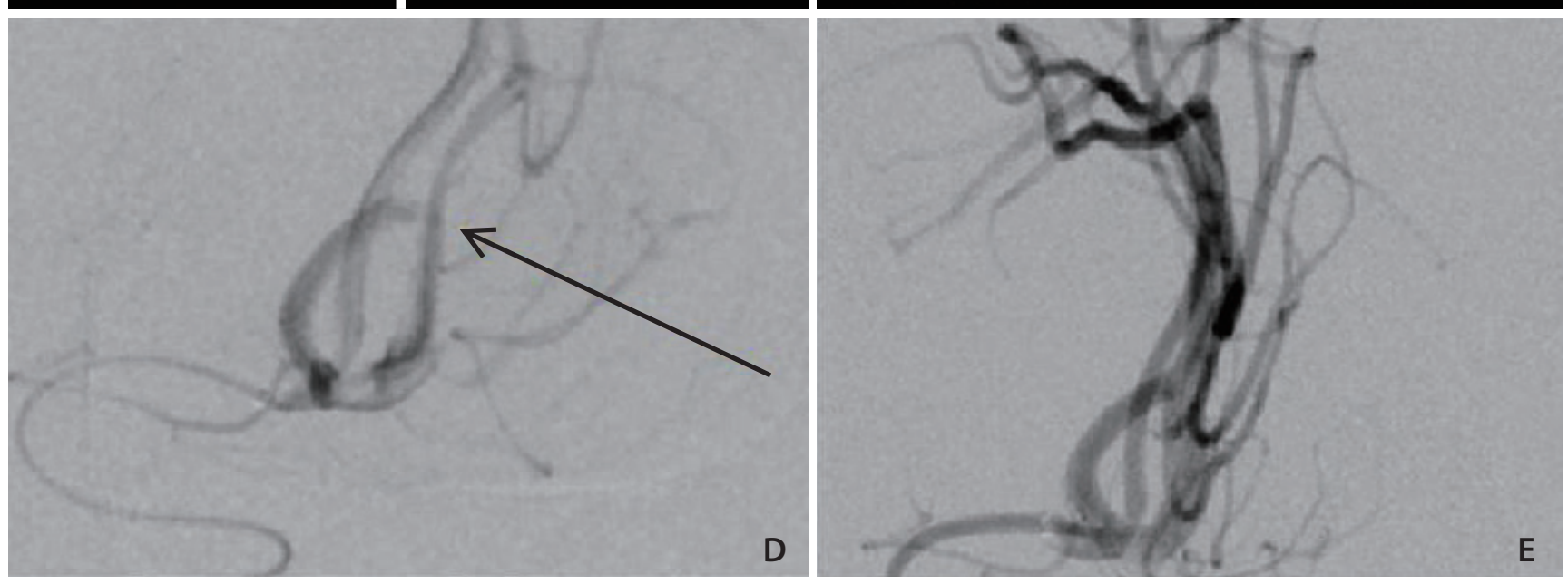

Fig. 1. Cranial images of an elderly patient. (A) Non-contrast scan with no early ischemic signs. (B) CTA with no occlusion of intracerebral arteries on first view. (C) CTP sequence. Mean transit time (MTT) delayed in the area of the right ACA, followed by a congruent cerebral blood flow (CBF) and cerebral blood volume (CBV) mismatch. (D) Interventional angiography of the right ACA before MT and verification of a triplication (arrow). (E) Interventional angiography of the right ACA after MT. CTA, computed tomographic (CT)-angiography; CTP, CT-perfusion; ACA, anterior cerebral artery; MT, mechanical thrombectomy. 
software; Forchheim, Germany). Beyond exclusion of an $\mathrm{ICH}$, no early ischemic signs were seen in the non-contrast scan (Fig. 1A). On the first orienting views, no occlusion of intracerebral arteries was detectable (Fig. 1B). However, in CTP the mean transit time in the area of arterial supply of the right ACA was delayed and a congruent cerebral blood flow and cerebral blood volume mismatch was seen (Fig. 1C). As this finding clearly indicates a vessel occlusion, a further much more detailed view on the CTA was performed, where ACA triplication was suspected. Thus, endovascular recanalization was initiated in accordance to German guidelines. ${ }^{10}$ Combination with intravenous thrombolysis was not performed, since trials have shown efficacy of intravenous thrombolysis or MT in "wake-up-stroke"-patients ${ }^{11-13}$ but still no trial has evaluated a dual recanalization concept in this population.

Interventional angiography revealed occlusion of the proximal A2-segment of the right ACA while confirming a triplication of this segment as an anatomical variation (Fig. 1D). Mechanical thrombectomy resulted in successful recanalization (thrombolysis in cerebral infarction 3, $\mathrm{TICl} 3$ ) and was performed without complications (Fig. 1E) and no definitive infarct-demarcation in follow-up CT. Due to the continuing unstable cardiac situation, the patient was transferred to our intensive care unit, post-interventionally.

In our advanced diagnostic examinations tachycardiac atrial fibrillation was detected as the underlying cause of the cerebral vascular occlusion.

\section{DISCUSSION}

Anatomical variations of the circle of Willis are well described in literature and have an estimated prevalence of $68.2 \pm 14.3 \% .^{14}$ Thus, it should be always been considered that the majority of AIS patients will exhibit one or more anatomic variations. In this context, triplications of the ACA and ACA-branches are described occasionally. Kapoor et al. ${ }^{6}$ found triplications of ACA in $2.3 \%$ of 1,000 specimen. The clinical significance of the triplication of ACA and ACA-branches is seen minor by some authors. ${ }^{7}$ In some cases the triplication is discussed as a risk factor leading to aneurysm. ${ }^{15,16}$

In modern diagnostic algorithms of patients with an acute cerebrovascular event, beyond non-enhanced cerebral CT scans, usually also a CTA is included. CTA is especially inevitable in detecting large vessel occlusions. Distal and/or small vessel occlusion can be overseen easily. Moreover, CTP can depict tissue-at-risk in the acute phase and can guide effective acute reperfusion treatment. ${ }^{17,18}$ Furthermore $\mathrm{CT}$ perfusion maps can improve the detection of vessel occlusions. ${ }^{19}$ Nonetheless, the indication for CTP in case of inconspicuous non-contrast and CTA scans is often discussed.

Summarizing, we describe a case of embolic stroke with an occlusion of the proximal A2-segment of a triplicated ACA which was only identified thanks to the additional CTP. The triplication of ACA is a rare anatomical variation, and the occlusion could have been overlooked in case of not performing the CTP sequences. In detecting distal and/or atypical vessel occlusions CTA might be limited in the acute setting, particularly for young residents performing the first view on call. CTP maps improve the diagnostic performance of vessel occlusion detection and should be part of the initial CT-diagnostic algorithm in AIS patients who are basically eligible for recanalization therapies, irrespective of inconspicuous initial findings in CTA.

\section{Fund}

None.

\section{Ethics Statement}

The Institutional Review Board (Ethics Committee of the Medical Faculty of the Ruhr University of Bochum) approved the publication of this material. According to the ethics committee of the Ruhr-University in Bochum this case can be reported as patient-data are kept anonymous.

Written informed consent was taken from patients for publication of this report.

\section{Conflicts of Interest}

The authors have no conflicts to disclose.

\section{Author Contributions}

Concept and design: CK. Analysis and interpretation: JCJ, DR, LT, RS, CL, FK, RG, and CK. Data collection: JCJ and FK. Writing the article: JCJ. Critical revision of the article: DR, LT, RS, CL, FK, $R G$, and CK. Final approval of the article: JCJ, DR, LT, RS, CL, FK, $R G$, and $C K$.

\section{ORCID}

Jeyanthan Charles James: https://orcid.org/0000-0002-7192-2120

Daniel Richter: https://orcid.org/0000-0001-6947-8350

Laura Tomaske: https://orcid.org/0000-0001-6437-1036 
Ruth Schneider: https://orcid.org/0000-0002-0997-2725

Carsten Lukas: https://orcid.org/0000-0002-8562-9697

Felix Kaemmerer: https://orcid.org/0000-0002-2506-7207

Ralf Gold: https://orcid.org/0000-0002-7223-3052

Christos Krogias: https://orcid.org/0000-0003-2965-4051

\section{REFERENCES}

1. Tsivgoulis G, Safouris A, Krogias C, Arthur AS, Alexandrov AV. Endovascular reperfusion therapies for acute ischemic stroke: dissecting the evidence. Expert Rev Neurother 2016;16:527-534

2. Pfaff J, Herweh C, Pham M, Schieber S, Ringleb PA, Bendszus $M$, et al. Mechanical thrombectomy of distal occlusions in the anterior cerebral artery: recanalization rates, periprocedural complications, and clinical outcome. AJNR Am J Neuroradiol 2016;37:673-678

3. Trepel M. Neuroanatomie: struktur und funktion, 5th ed. München: Urban \& Fischer; 2011 German

4. Kang SY, Kim JS. Anterior cerebral artery infarction: stroke mechanism and clinical-imaging study in 100 patients. Neurology 2008;70(24 Pt 2):2386-2393

5. Fawcett $E$, Blachford JV. The circle of Willis: an examination of 700 specimens. J Anat Physiol 1905;40(Pt 1):63.2-70

6. Kapoor K, Singh B, Dewan LI. Variations in the configuration of the circle of Willis. Anat Sci Int 2008:83:96-106

7. Ravikanth R, Philip B. Magnetic resonance angiography determined variations in the circle of Willis: analysis of a large series from a single center. Ci Ji Yi Xue Za Zhi 2019;31:52-59

8. Karatas A, Coban G, Cinar C, Oran I, Uz A. Assessment of the circle of Willis with cranial tomography angiography. Med Sci Monit 2015;21:2647-2652

9. Iqbal S. A comprehensive study of the anatomical variations of the circle of Willis in adult human brains. J Clin Diagn Res 2013;7:2423-2427

10. Ringleb PA, Hamann GF, Röther J, Jansen O, Groden C, Veltkamp
R. [Therapy of acute ischemic stroke - recanalisation therapy guideline]. Aktuelle Neurol 2016;43:82-91 German

11. Albers GW, Marks MP, Kemp S, Christensen S, Tsai JP, Ortega-Gutierrez S, et al.; DEFUSE 3 Investigators. Thrombectomy for stroke at 6 to 16 hours with selection by perfusion imaging. $N$ Engl J Med 2018;378:708-718

12. Nogueira RG, Jadhav AP, Haussen DC, Bonafe A, Budzik RF, Bhuva P, et al.; DAWN Trial Investigators. Thrombectomy 6 to 24 hours after stroke with a mismatch between deficit and infarct. NEngl J Med 2018;378:11-21

13. Thomalla G, Simonsen CZ, Boutitie F, Andersen G, Berthezene Y, Cheng B, et al.; WAKE-UP Investigators. MRI-guided thrombolysis for stroke with unknown time of onset. N Engl J Med 2018;379:611-622

14. Jones JD, Castanho P, Bazira P, Sanders K. Anatomical variations of the circle of Willis and their prevalence, with a focus on the posterior communicating artery: a literature review and meta-analysis. [published online ahead of print Jul 26, 2020] Clin Anat 2020

15. Sun C, Xv ZD, Yuan ZG, Wang XM, Wang LJ, Liu C. MSCT diagnosis of aneurysms associated with an unusual variant: atypical triplication anterior cerebral artery. Surg Radiol Anat 2012;34:777-780

16. Ureña FM, Ureña JGM, Almeida S, Rabelo NN, da Silva JR, Mandel $\mathrm{M}$, et al. Anterior communicating artery duplication associated with a triplication of anterior cerebral artery - a rare anatomical variation. Surg Neurol Int 2020;11:36

17. Thomalla G, Gerloff C. Acute imaging for evidence-based treatment of ischemic stroke. Curr Opin Neurol 2019;32:521-529

18. Simonsen CZ, Leslie-Mazwi TM, Thomalla G. Which imaging approach should be used for stroke of unknown time of onset? Stroke 2021;52:373-380

19. Becks MJ, Manniesing R, Vister J, Pegge SAH, Steens SCA, van Dijk EJ, et al. Brain CT perfusion improves intracranial vessel occlusion detection on CT angiography. J Neuroradiol 2019;46:124-129 